\title{
School liaison program supporting children with neurofibromatosis type 1: a model of care for children with chronic disease
}

\author{
Meredith A. Chambers, MEd ${ }^{1}$, David T. Miller, MD, $\mathrm{PhD}^{2}$ and Nicole J. Ullrich, MD, PhD ${ }^{1}$
}

Genet Med advance online publication 26 October 2017

\section{INTRODUCTION}

Neurofibromatosis type 1 (NF1) is a common autosomaldominant disorder with an incidence of 1:3,000 and an increased risk for development of tumors of the central and peripheral nervous systems. ${ }^{1,2}$ There is also increased risk for cognitive, learning, and social difficulties, affecting more than half of all individuals with NF1. ${ }^{3}$ Although there is no neurocognitive profile pathognomonic for NF1, there are more commonly observed deficits, including visual-spatial functioning, information integration, attention deficit disorder, memory, motor skills, and social skills. ${ }^{4,5}$ More than half of children with NF1 experience difficulty with language, executive functions, dyscalculia, and visual-spatial functions. ${ }^{6}$ In the school setting, these may present as academic and executive functioning deficits. Social cognitive dysfunction may also occur, which translates to challenges with peer relationships. ${ }^{5}$

Cognitive deficits in children with NF1 vary from mild (e.g., executive function issues) to severe (e.g., autism spectrum disorder), frequently requiring school-based special education services or specialized accommodations. Families and school teams often lack a clear understanding of the diagnosis and recommended services to support the education of children with NF1. The goals of this commentary are to introduce a proposed model of care, the Neurofibromatosis School Liaison Program (NF-SLP). A representative case of a child with NF1 with school-based challenges who received NF-SLP services is described. The commentary will present initial outcomes, strengths, challenges, and future directions using this diagnosisspecific educational intervention approach. We believe this type of program serves as a model of support for children with other chronic diseases that impact cognitive function.

\section{The NF-SLP model of care}

Individuals with NF1 face a unique set of challenges in school due to academic and executive functioning deficits as well as
Key Words: neurofibromatosis type 1; educational program; cognitive deficits; school advocacy

social cognitive dysfunction. There are no existing programs that specifically support the educational needs of children with NF1. To address this gap, we created the NF-SLP as part of the Multidisciplinary Neurofibromatosis Program at Boston Children's Hospital. The NF-SLP was modeled after an existing program for survivors of childhood cancer. ${ }^{7}$ The program provides cost-free, consultative services to parents and schools. It also seeks to ensure that children with NF1 gain full and appropriate access to the educational curriculum. The NF-SLP clinician teaches families to advocate for their child's learning needs. Collaboration with and education of school-based teams is provided to assist in understanding the effects of NF1 and associated medical conditions on learning and social functioning.

\section{The NF-SLP team}

\section{NF-SLP education specialist}

The NF-SLP education specialist is the primary provider of services and has a Master of Education degree concentrating in special education, with extensive knowledge of theories, principles, and concepts of both general and special education. The NF-SLP education specialist was trained by the medical team with regard to the NF-specific issues and attends NF clinic as well as education sessions, local symposia, and international research meetings on NF1. The NF-SLP education specialist is also a committee member for national organizations focusing on education of children with medical needs. The NF-SLP education specialist has a working knowledge of special education law at both the federal and state levels.

\section{Neuropsychologist}

A neuropsychologist with a strong knowledge of NF1 and its impacts on learning is an essential component of the NF-SLP. Ideally, the neuropsychologist has a doctoral degree and is board certified in clinical neuropsychology.

${ }^{1}$ Department of Neurology, Boston Children's Hospital, Boston, Massachusetts, USA; ${ }^{2}$ Department of Medicine/Division of Genetics and Genomics, Boston Children's Hospital, Boston, Massachusetts, USA. Correspondence: Nicole J. Ullrich (nicole.ullrich@childrens.harvard.edu) 
When educational concerns arise, the child is referred for comprehensive neurocognitive assessment. Neuropsychological evaluations serve as a baseline, identifying neurocognitive strengths and deficits. They expand on the school-based evaluation and provide alternate, detailed assessments. After testing is completed, the NF-SLP education specialist attends the feedback session with the family. The educational specialist attends school-based meetings, where results are shared with the school-based team and are typically incorporated into the individualized education program (IEP) or 504 plan. Testing is repeated every 2-3 years to assess changes in academic and cognitive growth.

\section{Referral to the school liaison program and initial contact}

The NF-SLP accepts any child with NF1 from our institution, ages 3 years through high school graduation or cessation of special education services (age 22 in Massachusetts). Referrals are initiated by a medical provider or parent with concerns about the child's academic and/or social functioning. At the time of referral, the parent/guardian completes an intake form, and provides contact information and a release form so the NFSLP provider can speak with the school. The NF-SLP typically reaches out to the family $24-72$ hours after the referral is initiated. There is no wait list. Parental concerns regarding school performance, social functioning, and school services are documented. Reviews of current educational documents are completed. Information from the child's school regarding academic and social functioning is assessed. The education specialist confers with the child's NF physician for input as to how current medical issues, concurrent medications, and potential treatment trajectory may impact the child in school. The NF-SLP provider then provides appropriate recommendations and guidance to parents and school-based teams.

\section{School liaison program support services}

The NF-SLP assists both families and schools in best supporting the needs of the student. Many educators are unfamiliar with the NF1 diagnosis or its impact on academic and social functioning. Through phone consultations, face-toface visits, and participation in school meetings (in person for families living within 60 miles of the hospital and otherwise by phone), the NF-SLP collaborates with and provides education to school-based teams. The NF-SLP helps to clarify results of evaluations performed in or outside of the school setting, such as neuropsychological testing. Assistance in the development of services, accommodations, and placement is also provided. When feasible, the NF-SLP also visits the school to observe the child's functioning within the academic environment.

Advocacy is a key component of the SLP. The NF-SLP education specialist assists the family in understanding their child's learning and social challenges. Parents are often unsure of what support services are available. The NF-SLP education specialist is able to provide parental education and guidance to help them become involved advocates while ensuring understanding of available supports for their child.
The NF-SLP education specialist has knowledge of federal and state special education laws. This knowledge is helpful in assisting families throughout the special education process. Disputes in service delivery or placement may occur between schools and parents. This can result in mediation or due process hearing; the NF-SLP education specialist is available to assist in resolving such disputes. The NF-SLP education specialist works directly with families and school-based teams to help locate assistance from community or state agencies where needed.

\section{Illustrative NF-SLP case}

The patient is a 9-year-old girl with maternally inherited NF1, in a general education public school third-grade classroom. Prior to accessing the NF-SLP, she underwent school-based academic evaluations. Results revealed below-average scores on at least one subtest in each academic area; however, the combined overall scores fell within the average range, thereby disqualifying her for special education services or individual accommodations. Parents reported anticipatory abdominal pain and headaches related to school attendance in addition to declining performance in reading, writing, and math. After ruling out other medical sources of the physical symptoms, she was referred for comprehensive neurocognitive assessment by a neuropsychologist. The NF-SLP then attended the feedback session with the parents. Results revealed significant visual-spatial, attention, working memory, and graphomotor deficits. An IEP was recommended. The NF-SLP education

Table 1 Neurofibromatosis School Liaison Program (NF-SLP) patient characteristics and service provision

\begin{tabular}{|c|c|}
\hline Active patients & 200 \\
\hline \multicolumn{2}{|l|}{ Patient characteristics } \\
\hline Male & $119(59.5 \%)$ \\
\hline Female & $81(40.5 \%)$ \\
\hline Age range & $2-22$ years \\
\hline Family history of NF1 & $52(26 \%)$ \\
\hline Live in state (Massachusetts) & $174(87 \%)$ \\
\hline Attend public school & $189(94.5 \%)$ \\
\hline \multicolumn{2}{|l|}{ NF-SLP service provision } \\
\hline $\begin{array}{l}\text { NF-SLP specialist attended school-based meeting in } \\
\text { person }\end{array}$ & 127 \\
\hline NF-SLP specialist attended meeting by phone & 23 \\
\hline Average meeting length & 2.5 hours \\
\hline \multicolumn{2}{|c|}{$\begin{array}{l}\text { SLP service access (consult, document review, attend school/feedback } \\
\text { meeting): }\end{array}$} \\
\hline Total no. accessing at least one SLP service & 200 \\
\hline Total no. accessing $>1$ SLP service & 176 \\
\hline $\begin{array}{l}\text { \% Meetings resulting in expanded services/ } \\
\text { accommodations }\end{array}$ & $98 \%$ \\
\hline Current 504/IEP & 193 \\
\hline New 504/IEP created as a result of SLP involvement & 31 \\
\hline
\end{tabular}

IEP, individualized education plan; NF1, neurofibromatosis 1; NF-SLP, Neurofibromatosis School Liaison Program. 
Table 2 Common academic challenges and interventions for children with NF1

\begin{tabular}{|c|c|c|c|c|}
\hline Common academic challenges & Interventions & Provider(s) & $\begin{array}{l}\text { Service } \\
\text { delivery }\end{array}$ & Service vehicle \\
\hline \multicolumn{5}{|l|}{ Reading } \\
\hline Phonemic awareness & Technology & General educator & Inclusion & General \\
\hline Phonics & Explicit instruction & Special educator & Pull out & education RTI \\
\hline Vocabulary & Language-based reading & Instructional assistant & & 504 plan \\
\hline Fluency & program & & & IEP \\
\hline \multicolumn{5}{|l|}{ Comprehension } \\
\hline \multicolumn{5}{|l|}{ Writing } \\
\hline Phonemic awareness & Technology & General educator & Inclusion & General \\
\hline Phonics & Explicit instruction & Special educator & Pull out & education RTI \\
\hline Vocabulary & Language-based reading & Instructional assistant & & 504 plan \\
\hline Fluency & program & & & IEP \\
\hline \multicolumn{5}{|l|}{ Comprehension } \\
\hline \multicolumn{5}{|l|}{ Mathematics } \\
\hline Number sense & Technology & General educator & Inclusion & General \\
\hline Calculation & Repetition & Special educator & Pull out & education RTI \\
\hline Multistep problem solving & Models & Instructional assistant & $\mathrm{RTI}$ & 504 plan \\
\hline Vocabulary & Step-by-step instruction & & & IEP \\
\hline Geometry & Teach key vocabulary & & & \\
\hline \multicolumn{5}{|l|}{ Application } \\
\hline \multicolumn{5}{|l|}{ Executive function } \\
\hline Planning/organizing & Technology & General educator & Inclusion & General \\
\hline Decision making & Calendar/organizer & Special educator & Pull out & education RTI \\
\hline Complex problem solving & Scaffolding tasks & Instructional assistant & & 504 plan \\
\hline Transitioning & Sequential lists & & & IEP \\
\hline Impulse control & Visual and written instruction & & & \\
\hline Focus and attention & Repeat instructions & & & \\
\hline Social awareness & Set routines/limits & & & \\
\hline \multicolumn{5}{|l|}{ Speech and language } \\
\hline Articulation/intelligibility & Model articulation and sound & Speech and language pathologist & Inclusion & IEP \\
\hline Social pragmatics & production & & Pull out & \\
\hline Expressive/receptive language & Situational awareness of & & & \\
\hline Vocabulary & language & & & \\
\hline \multicolumn{5}{|l|}{ Occupational therapy } \\
\hline Fine motor (handwriting, cutting, finger & Fine motor/dexterity exercises & Occupational therapist & Inclusion & IEP \\
\hline grasp, tracing) & Visual/perceptual/motor training & & Pull out & 504 plan \\
\hline Motor planning/praxis skills & Sensory processing & & & \\
\hline & Assistive technology & & & \\
\hline \multicolumn{5}{|l|}{ Physical therapy } \\
\hline Balance/coordination & Strengthening exercise & Physical therapist and/or physical & Pull out & IEP \\
\hline Hypotonia & Motor therapy & education teacher & & 504 plan \\
\hline Running/catching/throwing & Visual perceptual/motor training & & & \\
\hline Climbing/descending stairs & Sensory processing & & & \\
\hline \multicolumn{5}{|l|}{ Social functioning } \\
\hline Concrete thinking & Direct, explicit instruction of & School psychologist & Pull out & Counselor \\
\hline Inflexibility & social skills & School social worker & Inclusion & IEP \\
\hline Sensory integration & Role play Video modeling & General educator & $1: 1$ & 504 plan \\
\hline Initiating and maintaining conversations/ & Social skills group & Special educator & & \\
\hline friendships & Counseling & Instructional assistant & & \\
\hline \multicolumn{5}{|l|}{ Understanding facial/social cues, sarcasm } \\
\hline \multicolumn{5}{|l|}{ Following conversations } \\
\hline \multicolumn{5}{|l|}{ Immaturity } \\
\hline Personal space & & & & \\
\hline
\end{tabular}

IEP, individualized education program; NF1, neurofibromatosis 1; RTI, response to intervention. 
specialist attended a school-based meeting, informing the school education team (principal, occupational therapist, school psychologist, special educator, and two general educators) about the impact of NF1 on learning and social functioning. The neuropsychological evaluation was reviewed. The findings from the neurocognitive assessment, which supplemented school-based testing, and the advocacy by the NF-SLP education specialist helped to secure an IEP. Individualized goals and objectives included occupational therapy, access to the school adjustment counselor for anxiety, and direct instruction by a special educator in all core academics. In this case, the time from referral for neurocognitive testing to final report was 6 months and another month for an executed IEP. The parents have a comprehensive understanding of their child's cognitive strengths and limitations. They are pleased with the results of the advocacy of the NF-SLP in securing special education services. Coincident with introduction of the IEP and supportive services, school anxiety, abdominal pain, and headaches dissipated significantly.

\section{NF-SLP initial outcomes}

One educational specialist currently carries the caseload for all patients in the program. We have provided analysis for the first 200 individuals to access the program. Table $\mathbf{1}$ delineates patient characteristics and service provision. Of these, $100 \%$ now receive expanded educational services or accommodations after NF-SLP input. Formal educational plans (504 or IEP) are received by $98 \%$ of patients accessing NF-SLP services, of which 31 were newly created. Table 2 provides an outline of academic challenges common to children with $\mathrm{NF} 1$ as well as recommended academic services and service providers. General education services are provided to all students. A 504 document contains accommodations and modifications to assist the student in the general education setting. The IEP provides direct services by the special education team.

\section{DISCUSSION}

The types of academic services and supports a child with NF1 may need can be numerous and are likely to vary throughout the child's education. There can be any number of challenges encountered when advocating for academic/support services during a school-based team meeting. The following challenges are common: essential team members absent, team members dismissed during the meeting to attend other meetings, limited time frame for extension of meetings to another session, school-based testing results not available, IEP goals not being implemented, and little to no data collection on annual goals. With continued communication and compromise, most challenges can be overcome.

From a programmatic point of view, considerations such as cost/funding sources and staffing are important when developing a school liaison program. Program costs include salary, travel expenses, administrative services, and office space. Additionally, NF-SLP provider services are not reimbursable by insurance. Due to time and financial constraints, the program is offered cost-free and is only offered to those who are patients of the NF program at our institution. Because the NF-SLP cannot currently bill for services, the senior author (N.J.U.) raised philanthropic funds so that the program could remain cost-free to patients.

Because many parents themselves carry the NF1 diagnosis and may have a history of learning difficulties, it can be even more challenging for them to advocate for their child. Our program model offers parents ongoing, individual training with the NF-SLP in the areas of navigating the special education process, understanding school-based assessments, and IEP and/or 504 documents, among other topics. The program provides supplementary group training sessions for parents on topics such as advocacy, guardianship, and postsecondary services, offering a much-needed additional source of assistance.

\section{CONCLUSION}

Cognitive deficits in children with NF1 are common and varied. The NF-SLP seeks to help children with NF1 access educational services. It also empowers both parents and school systems through continued collaborative consultation, advocacy, and support services to help ensure a successful education experience. The program is gathering data on parent understanding of academic needs, satisfaction with education services, perceived academic success, and impact of NF-SLP involvement. It is our hope that this model can be replicated for children with other chronic medical conditions in which cognitive and medical issues impact academic functioning.

\section{DISCLOSURE}

D.T.M. is a part-time clinical consultant to Claritas Genomics (non-equity professional services agreement). The other authors declare no conflict of interest.

\section{REFERENCES}

1. Huson SM, Harper PS, Compston DA. Von Recklinghausen neurofibromatosis. A clinical and population study in south-east Wales. Brain. 1988;111(Pt 6):1355-1381.

2. Friedman JM. Neurofibromatosis 1. In: Pagon RA, Adam MP, Ardinger $\mathrm{HH}$, et al. (eds). GeneReviews. University of Washington: Seattle, WA, 2014.

3. Hyman SL, Shores A, North KN. The nature and frequency of cognitive deficits in children with neurofibromatosis type 1. Neurology. 2005;65: 1037-1044.

4. North K, Joy P, Yuille D, Cocks N, Hutchins P. Cognitive function and academic performance in children with neurofibromatosis type 1. Dev Med Child Neurol. 1995;37:427-436.

5. Allen T, Willard VW, Anderson LM, Hardy KK, Bonner MJ. Social functioning and facial expression recognition in children with neurofibromatosis type 1. J Intellect Disabil Res. 2016;60:282-293.

6. Payne JM, Moharir MD, Webster R, North KN. Brain structure and function in neurofibromatosis type 1: current concepts and future directions. J Neurol Neurosurg Psychiatry. 2010;81:304-309.

7. Northman L, Ross S, Morris M, Tarquini S. Supporting pediatric cancer survivors with neurocognitive late effects: a model of care. J Pediatr Oncol Nurs. 2015;32:134-142. 